\title{
The efficacy of subcutaneous sumatriptan in the treatment of recurrence of migraine headache
}

\author{
R E Cull, W H Price, A Dunbar
}

\begin{abstract}
Objectives-To investigate the efficacy of a second subcutaneous dose of $6 \mathrm{mg}$ sumatriptan in the treatment of recurrence of headache after successful treatment of a migraine attack with an initial $6 \mathrm{mg}$ dose. Methods-In a prospective, randomised, placebo controlled, double blind, parallel group study, 803 patients were treated for one to three migraine attacks with severe or moderate headache with a subcutaneous injection of $6 \mathrm{mg}$ sumatriptan. Any subsequent recurrence of migraine headache was treated with a randomised second injection of sumatriptan or placebo. Recurrence was defined as a headache of moderate or severe intensity occurring 1-24 hours after the initial dose in a patient whose headache had been relieved by sumatriptan (reduction of headache severity from severe or moderate to mild or none after one hour).

Results-Headache recurrence was reported by $10 \%-15 \%$ of patients. At each attack, $6 \mathrm{mg}$ sumatriptan given subcutaneously was significantly $(P<0.0005)$ more effective than placebo at relieving recurrent headache after one hour $(84 \%-93 \% \quad v \quad 31 \%-50 \%$ of patients); $76 \%-83 \%$ of patients reported headache relief one hour after the initial dose of sumatriptan. Sumatriptan was generally well tolerated.

Conclusions-Up to $15 \%$ of patients with migraine experience significant recurrence of headache after successful treatment with subcutaneous sumatriptan, and this recurrence is effectively treated by a further dose of subcutaneous sumatriptan.
\end{abstract}

$(\Im$ Neurol Neorosurg Psychiatry 1997;62:490-495)

Department of Clinical Neurosciences, Western General Hospital, Crewe Road, Edinburgh, EH4 2XU,

UK

RE Cull

W H Price

A Dunbar

Correspondence to:

Dr R E Cull, Department of

Clinical Neurosciences,

Western General Hospital,

Western General Hospital,
Crewe Road, Edinburgh,

EH4 2XU, UK.

Received 7 May 1996

and in final revised form

16 December 1996

Accepted 23 December 1996 (probably 5- $\mathrm{HT}_{1 \mathrm{~B}}$ subtype) which mediate vasoconstriction of cranial blood vessels. ${ }^{12}$ The primary mechanisms of action of sumatriptan may be related to these vasoconstrictive effects, but the drug may also block neurogenic inflammation and neural transmission via activation of $5-\mathrm{HT}_{1}$ receptors on trigeminal nerve terminals. ${ }^{1}$
In clinical trials, sumatriptan given subcutaneously or orally is an effective and well tolerated acute treatment for migraine. ${ }^{34}$ At least $70 \%$ of patients report headache relief within one hour after a subcutaneous injection of 6 mg sumatriptan in comparison with $22 \%-31 \%$ of those on placebo, ${ }^{5-7}$ and efficacy is maintained in long term use (up to one year) with no evidence of tachyphylaxis. ${ }^{89}$ However, these studies were designed to evaluate relief of headache and other symptoms of migraine, and took no account of the severity of recurrent headache or of the use of any additional non-study medication in the intervening period.

Although a second dose of sumatriptan after one hour is not effective in treating patients who do not respond to an initial dose, ${ }^{5-7}$ an appropriately timed second dose might be of value in treating recurrence of headache. The study reported here was designed to investigate prospectively the incidence of recurrence of headache after subcutaneous sumatriptan and the efficacy of a further dose of subcutaneous sumatriptan in treating the recurrent migraine headache.

\section{Patients and methods}

STUDY DESIGN

This was a randomised, placebo controlled, double blind, parallel group study carried out in 192 general practice centres and 12 hospital centres in the United Kingdom. The patients treated themselves outside the clinic, and each patient remained in the study for three months or until three migraine attacks had been treated, whichever was the sooner.

The trial was conducted in accordance with the Declaration of Helsinki 1964. Approval was obtained from the ethics committee of each of the participating hospitals and from an independent central ethics committee for the general practice centres. Patients gave their written consent before entering the trial. Data were collected on standardised forms and collected by Glaxo Wellcome study monitors. The database was held and analysed by Statistics and Data Management, Glaxo Wellcome UK Ltd, Stockley Park West, Uxbridge, Middlesex.

\section{SELECTION OF PATIENTS}

Men and women aged between 18 and 65 years, who met the International Headache Society's criteria for migraine with or without aura, ${ }^{9}$ were enrolled in the study. They had a current migraine history of at least six months 
(age at onset $<50$ years), with between one and four severe or moderately severe attacks per month and at least 24 hours of freedom from headache between attacks. Patients taking prophylactic medications for migraine were included if they had received this therapy, at a constant dose, for the previous three months and continued on the same prophylactic treatment regimen throughout the study. Patients were excluded if they had a history of ischaemic heart disease, uncontrolled hypertension (diastolic blood pressure $>95 \mathrm{~mm}$ $\mathrm{Hg}$ ), or other clinically concurrent medical condition, had hemiplegic migraine, were pregnant or breast feeding, or were concurrently taking ergotamine, daily analgesic or antiemetic therapy, monoamine oxidase inhibitors, 5-HT reuptake inhibitors, or lithium. Patients who had misused ergotamines, alcohol, or other drugs were also excluded.

\section{TREATMENTS}

At the first visit to the hospital or general practice centre (week 0 ), patients were given a brief medical examination, and their migraine history and pertinent medical history were recorded. Migraine diary cards were issued and patients were asked to stop any ergotamine or sumatriptan therapy, and to take no ergotamines for the duration of the study. The occasional use of analgesics was permitted, provided that they were not taken within six hours before the study medication.

The patients were randomly allocated to one of two treatment groups (groups A and B). Starting from week 2, patients in both groups took $6 \mathrm{mg}$ sumatriptan subcutaneously at the onset of a migraine headache of moderate or severe intensity (dose 1). For the treatment of headache recurrence only (dose 2) group A took $6 \mathrm{mg}$ sumatriptan subcutaneously and group B took placebo. Patients self administered study medication with a modified Owen Mumford autoinjector. Headache intensity was graded by the patients on the diary cards as severe (grade 3), moderate (grade 2), mild (grade 1), or none (grade 0 ). Recurrence of headache was defined as a headache of moderate or severe intensity that occurred between one and 24 hours after the first dose of sumatriptan in a patient whose migraine headache was initially relieved by dose 1 .

If relief of headache was inadequate (headache grade 3 or 2) one hour after dose 1 or 2, patients could take rescue medication (not ergotamine containing drugs or commercially available sumatriptan). Patients who had taken rescue medication after dose 1 for relief of persistent or recurrent headache were excluded from the analysis for that attack. Patients treated their next migraine attack with study medication provided that at least 24 hours had elapsed since their last study treatment. The maximum permitted dose of sumatriptan in 24 hours was two $6 \mathrm{mg}$ injections.

The patients returned to the clinic at four week intervals for up to 14 weeks. At these follow up visits the diary cards and treatment packs were checked for compliance with the study protocol. Patients who had treated three migraine attacks were considered to have completed the study.

EVALUATION OF EFFICACY, TOLERABILITY, AND SAFETY

The primary end point of clinical efficacy was the relief of the recurrent headache (from severe or moderate to mild or none) at one hour after treatment with dose 2 . Secondary end points included relief of headache one hour after dose 1 , the requirement for rescue medication after two doses of study medication, shifts in headache severity (time of dosing $v$ one hour after dosing), and the patient's global response to treatment. Global response was assessed at the final follow up visit when the patients graded their overall assessment of the treatment efficacy as ineffective, poor, reasonable, good, or excellent.

The tolerability of sumatriptan was assessed by monitoring adverse events in all patients treated with study medication. An adverse event was defined as any untoward clinical event that occurred during the trial, irrespective of its relation to the study treatment. Investigators gave their opinion of the relation between the adverse event and the study drug (not related, unlikely to be, possibly, probably, or almost certainly related). Additional safety assessments included heart rate and blood pressure measurements, which were recorded before treatment (visit 1-week 0). A 12 lead ECG was taken if a patient had an adverse event involving cardiac symptoms (chest pain, tightness) during the study and if the investigator considered this to be a useful supplementary investigation. The ECGs were assessed by an independent cardiologist.

\section{STATISTICAL METHODS}

The percentage of patients with headache relief one hour after treatment of a recurrent headache with placebo was estimated to be $20 \%$. Data on 48 patients per treatment group were required to have a $90 \%$ chance of detecting a $30 \%-50 \%$ difference between sumatriptan and placebo for the treatment of a headache recurrence using a two sided $5 \%$ significance level. Allowing for a $77 \%$ success rate with the first dose of sumatriptan for the treatment of the initial migraine attack, and a $30 \%$ incidence of headache recurrence among these patients, 208 patients per treatment group were required. Sample size calculations were based on the method for comparing two binomial proportions described by Machin and Campbell. ${ }^{10}$

The two treatment groups were compared, using the normal approximation to the bionomial distribution, with regard to the proportions of patients with a recurrence, with relief of headache recurrence, and needing rescue medication. Comparisons between the two groups in the patients' global response to treatment were made using the Wilcoxon rank sum test. Efficacy data for the first, second, and third migraine attacks were analysed separately, and all statistical tests were two sided. 
Table 1 Demographic and migraine characteristics of the study population

\begin{tabular}{lcc}
\hline Total population & $\begin{array}{c}\text { Group } A \\
n=443\end{array}$ & $\begin{array}{c}\text { Group } B \\
n=438\end{array}$ \\
Men (n (\%)) & $85(19)$ & $70(16)$ \\
Women (n (\%)) & $358(81)$ & $368(84)$ \\
Age (y) (mean (SD)) & $41(10 \cdot 8)$ & $40 \cdot 5(10 \cdot 3)$ \\
Weight (kg)(mean (SD)) & $68 \cdot 9(14 \cdot 6)$ & $69 \cdot 2(15 \cdot 2)$ \\
Migraine history (n (\%)) & & \\
Frequency: & $385(87)$ & $388(89)$ \\
1-4 attacks/month & $58(13)$ & $49(11)$ \\
1-4 attacks/week & 0 & 1 \\
Daily & $223(50)$ & $207(47)$ \\
Type: & $75(17)$ & $74(17)$ \\
Without aura & $145(33)$ & $157(36)$ \\
With aura & $2(<1)$ & $1(<1)$ \\
Both & $101(23)$ & $97(22)$ \\
Severity: & $340(77)$ & $340(78)$ \\
$\quad$ Mild & & \\
Moderate & & \\
Severe & & \\
\hline
\end{tabular}

- safety data were not analysed statistically. All patients who treated one or more attacks with study medication were included in the safety population. Adverse events that occurred on more than one occasion in any patient were reported each time the event occurred.

\section{Results}

STUDY POPULATION

A total of 924 patients were enrolled into the study, and 881 entered the treatment phase: 433 patients were randomised to group A (sumatriptan for recurrence) and 438 were randomised to group B (placebo for recurrence). The two groups had similar demographic and migraine characteristics (table 1), incidence of concomitant diseases, and medication. Most patients were women and experienced one to four severe or moderate attacks per month of migraine with or without aura. More patients in group A $(22 \%)$ than in group B $(17 \%)$ had taken prophylactic medication for migraine in the three months before entering the study. The most common drugs for prophylaxis were pizotifen and propranolol, which together accounted for $70 \%$ (group A) and $83 \%$ (group B) of the prophylactic drugs used. Other drugs used included clonidine hydrochloride and amitriptyline hydrochloride.

During the course of the study 60 patients in group A $(14 \%)$ and 58 patients in group B

Figure 1 Incidence of recurrence of migraine headache 1-24 hours after headache $1-24$ hours after
initial treatment with $6 \mathrm{mg}$ subcutaneous sumatriptan. Group A: $6 \mathrm{mg}$ sumatriptan $+6 \mathrm{mg}$ sumatriptan (for recurrence only); group B: $6 \mathrm{mg}$ sumatriptan + placebo (for recurrence only).

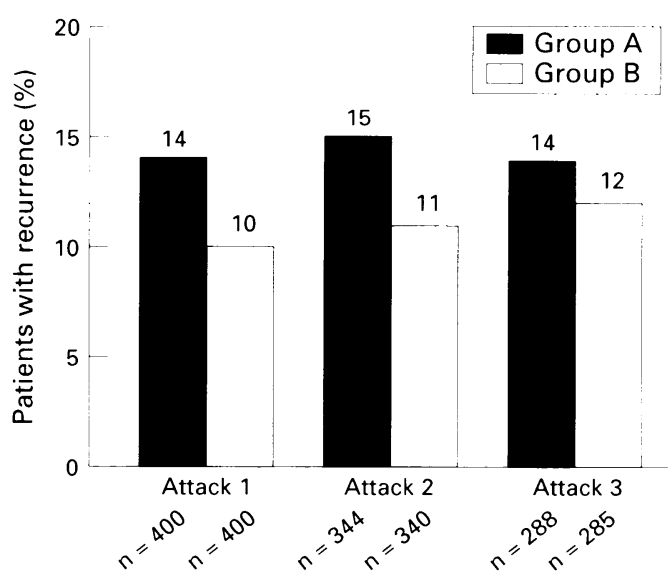

(13\%) were withdrawn. In group A, the main reasons for withdrawal were patients asking to withdraw (23 patients, 5\%), failure to return for follow up visits (22 patients, 5\%), and adverse events (17 patients, $4 \%$ ). In group B, 20 patients $(5 \%)$ withdrew because of adverse events, $13(3 \%)$ wished to withdraw, and 15 (3\%) did not return for follow up.

More than $64 \%$ of patients in each group treated three attacks during the study period. The total samples of patients with one, two, and three attacks were 400,344 , and 288 respectively, in group A, and 400, 340, and 285 respectively in group $B$.

\section{INCIDENCE OF RECURRENCE}

Only those patients whose recurrent headaches met the defined criteria and who had complied strictly with the assessment timetable and medication protocols were included in the data analyses. Headache recurrence during three attacks was experienced by $14 \%-15 \%$ of those randomised to receive a second dose of sumatriptan and by $10 \%-12 \%$ of those who were randomised to receive placebo (fig 1).

\section{EFFICACY}

Treatment of recurrence

At one hour after treatment of a recurrence, relief of headache (from grade 3 or 2 to grade 1 or 0) across the three attacks was reported by $84 \%-93 \%$ of patients who took sumatriptan and by $31 \%-50 \%$ of those who took placebo (fig 2). For each of the three attacks there was very strong evidence of a true treatment difference in favour of sumatriptan in the proportions of patients with headache relief one hour after treatment of recurrence $(\mathrm{P}<0.0005)$. For attack 1, the estimate of the true treatment difference was 34 percentage points (pp) in favour of group A $(95 \%$ confidence interval 15-52 pp). For attacks 2 and 3 the estimate and $95 \%$ confidence intervals were $54(36-72)$ pp and $51(33-70)$ pp respectively.

At each attack, subsequent rescue medica-

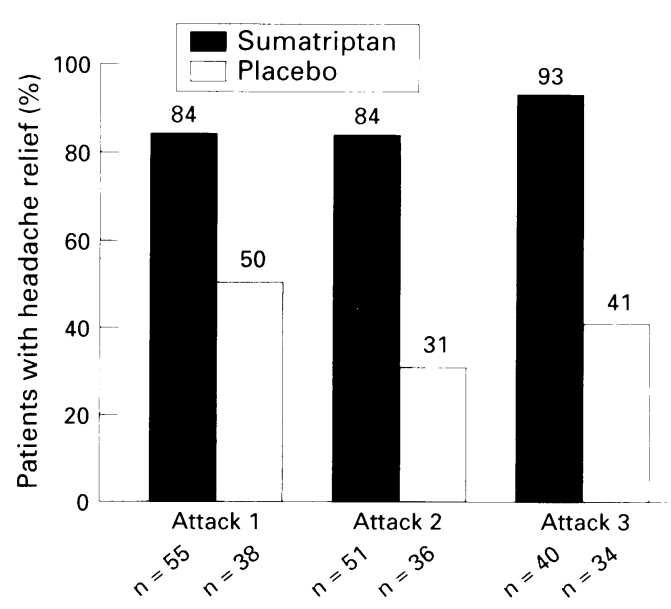

Figure 2 Headache relief one hour after treatment of recurrence of migraine headache with $6 \mathrm{mg}$ subcutaneous sumatriptan or placebo. Headache relief was defined as a reduction in severity of headache from grade 3 or 2 to grade 1 or 0. 
Figure 3 Use of rescue after treatment of $a$ recurrence of migraine headache with $6 \mathrm{mg}$ subcutaneous sumatriptan or placebo. medication from one hour

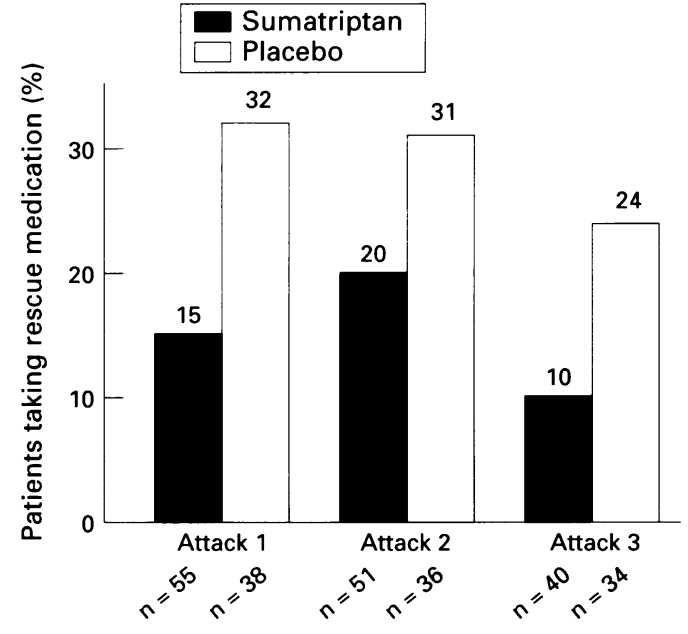

tion was required by more patients who took placebo to treat headache recurrence than by those who took sumatriptan (fig 3). For the first attack the difference between the two treatment groups in this respect neared significance $(P=0.056)$.

Headache relief after the first dose sumatriptan More than $76 \%$ of patients in both treatment groups obtained headache relief one hour after dose 1 (6 mg sumatriptan given subcutaneously) at each attack, and $41 \%-50 \%$ were headache free. These data are uncontrolled but are in keeping with published placebo controlled studies. ${ }^{7}$ Most patients $(75 \%-80 \%)$ did not require rescue medication.

\section{Patients' assessment of treatment}

Of those patients who gave their opinion at the end of the study period, $80 \%$ in group $A$ and $78 \%$ in group B rated the efficacy of the treatment as good or excellent.

Tolerability and safety

A total of 402 patients in group A and 401 patients in group $B$ treated one or more attacks with study medication. In total, 1033 and 1025 attacks were treated in groups $A$ and $B$ respectively.

After treatment, $58 \%$ of patients in group A reported a total of 970 adverse events, and

Table 2 Most frequent adverse events * that occurred after the study medication had been started

\begin{tabular}{|c|c|c|}
\hline \multirow[b]{2}{*}{ Adverse event } & \multicolumn{2}{|c|}{ Percentage of attacks with adverse event } \\
\hline & $\begin{array}{l}\text { Group A } \\
(6 \text { mg sumatriptan }+ \\
6 \text { mg sumatriptan) }\end{array}$ & $\begin{array}{l}\text { Group B } \\
\text { ( } 6 \text { mg sumatriptan }+ \\
+ \text { placebo) }\end{array}$ \\
\hline Nausea/vomiting & 11 & 8 \\
\hline Dizziness/vertigo & 12 & 6 \\
\hline Tingling & 9 & 5 \\
\hline Injection site reaction & 4 & 5 \\
\hline Feeling of heaviness & 1 & 6 \\
\hline Warm/hot sensation & 2 & 4 \\
\hline Paraesthesia & 4 & 2 \\
\hline Chest symptoms & 3 & 3 \\
\hline Fatigue/malaise & 3 & 2 \\
\hline Throat symptoms & 3 & 2 \\
\hline No of attacks treated & 1033 & 1025 \\
\hline Total No of adverse events $\dagger$ & 971 & 912 \\
\hline No of patients with adverse events & $235(58 \%)$ & $220(55 \%)$ \\
\hline
\end{tabular}

^Events that occurred in $\geqslant 3 \%$ of attacks in either group.

†Some patients reported more than one symptom.
$55 \%$ of patients in group B reported a total of 912 adverse events. Table 2 shows the most often reported adverse events. Injection site reactions occurred in $9 \%-11 \%$ of treatments. Most events were mild to moderate in severity ( $84 \%$ in group A and $84 \%$ in group B), and more than $96 \%$ had resolved at the time of assessment.

Sixteen patients in group A (4\%) and 19 patients $(5 \%)$ in group B withdrew from the study because of adverse events after beginning the study medication. The most common reasons for withdrawal due to adverse events were nausea and tightness in the chest. Three per cent of patients in each group reported chest symptoms after sumatriptan. Fifteen patients had 12 lead ECGs taken after such symptoms and all ECGs were assessed as normal by the independent cardiologist.

\section{Discussion}

This study was designed prospectively to ascertain, in a large clinical trial, the incidence of recurrence of migraine headache after successful treatment with $6 \mathrm{mg}$ subcutaneous sumatriptan. The definition of headache recurrence used was precise and likely to be of clinical relevance. The efficacy of a second subcutaneous dose of $6 \mathrm{mg}$ sumatriptan for the treatment of the recurrent headache was also assessed according to strictly defined criteria.

The patient population entered into the present study was similar in demographic characteristics to the general migraine population. Most patients were women, who had had migraine attacks for more than 15 years (median) and most attacks were of migraine without aura. Patients were severely affected by their attacks, reporting one to four migraine attacks per month. The attacks were typically severe in intensity, and lasted from several hours to several days. Although more patients in group A $(22 \%)$ had taken prophylactic medication for migraine than in group $B$ $(17 \%)$, it is unlikely that this had any significant effect on severity or duration of headache. Recent studies have shown that pizotifen does not have a significant effect on severity of attacks. ${ }^{11}$

The overall incidence of recurrence was $10 \%-15 \%$ after a single $6 \mathrm{mg}$ dose of subcutaneous sumatriptan during this study. This rate of recurrence is much lower than that reported in earlier studies in which a precise definition of recurrence was not used. Recurrence over 48 hours was reported by $46 \%$ of patients who administered $6 \mathrm{mg}$ sumatriptan subcutaneously themselves, ${ }^{7}$ and within 24 hours by $38 \%$ of patients given subcutaneous injections of $6 \mathrm{mg}$ sumatriptan by a physician. ${ }^{6}$ Patients in these studies were asked only to record whether their headaches had returned during the specified period, with no attempt being made to verify that the returning headache was a migraine, and no account was taken of the use of rescue or non-study medication. It is likely, therefore, that the recurrent headache reported by some of the patients was a mild 
recovery phase headache which would not always warrant further treatment. In the present study mild recurrent headache, after dose 1 , was reported by only $2 \%-4 \%$ of patients in each attack. Including these mild recurrent headaches in the analysis would therefore not greatly effect the results of this study.

Sumatriptan is a drug with a relatively short half life (about two hours) after subcutaneous administration. ${ }^{12}$ Plasma concentrations of the drug decrease very rapidly after injection, and are low by five to seven hours after administration. By contrast, a migraine attack may last up to 72 hours. The recurrence of a truly migrainous headache may therefore be the result of the migraine attack outlasting the duration of the effect of the treatment. ${ }^{13}$ This recurrent headache should not be confused with rebound headache, which can occur in patients who use medication very frequently, often daily, and in excessive doses. Such patients may develop drug induced headache which becomes worse with continuing medication, but discontinuation of treatment can lead to the development of a drug withdrawal headache. ${ }^{14}{ }^{15}$ Studies on the long term pattern of use of sumatriptan have disclosed no evidence of any such dose escalation, ${ }^{16}$ but occasional cases of rebound headache have been reported in patients misusing sumatriptanthat is, taking regular daily doses. ${ }^{17} 18$

Sumatriptan was effective in treating the recurrence of the migraine headache. Over three attacks, $84 \%-93 \%$ of patients reported headache relief one hour after taking $6 \mathrm{mg}$ sumatriptan subcutaneously to treat a recurrence, in comparison with $31 \%-50 \%$ of patients who took placebo. The difference between the two treatment groups was highly significant $(\mathbf{P}<0.0005)$. The response to placebo was quite high, and this may be related to the high expectancy of the patients, as both treatment groups took $6 \mathrm{mg}$ subcutaneous sumatriptan as dose 1 to treat the initial migraine attack. In this study data were gathered from patients who had treated one, two, or three attacks. Although some patients therefore may have contributed two or three sets of data, each attack was analysed separately.

This study was the first large scale trial undertaken in general practice with sumatriptan in which the patients self administered the drug using an autoinjector. This method of administration proved to be very acceptable to the patients. About $80 \%$ of patients in both treatment groups rated the efficacy of the medication as good or excellent, and more than $80 \%$ said they would take the medication again. More than 800 patients treated one or more migraine attacks with subcutaneous sumatriptan, but only one patient reported a faulty autoinjector, and only three were unable to self inject. The incidence of injection site reactions was low, with reactions occurring in about $10 \%$ of attacks - a level of incidence similar to that in earlier clinical trials of sumatriptan given with this autoinjector. ${ }^{7}$ Only two patients withdrew from the study because of reactions at the injection sites.
In conclusion, subcutaneous sumatriptan given by the patients themselves with an autoinjector is an effective and well tolerated treatment for migraine. A second $6 \mathrm{mg}$ dose was effective in relieving recurrence of headache, which was reported by a minority of patients. The efficacy of sumatriptan was maintained over treatment of up to three attacks.

The study was supported by Glaxo Wellcome UK Ltd, Stockley Park West, Uxbridge, Middlesex, UB1 1 1BT

The following doctors participated in the trial:

Dr AJ Hulme and Mr A Browning, (GlaxoWellcome Uk Ltd.) Aarons BM, Abbott RJ, Acharya HK, Adams RM, Aitchison WRC, Allen A, Anand $H$, Anand MS, Anderson EM, Anderson AMR, Arastu ZH, Arthur CP, Astles JG, Atherton MTC, Atkin M, Babinskyj RM, Ballantine DI, Barbour J, Barnard PD, Berger AB, Bhatia IL, Bhutani HC, Birrell DH, Blagden MD, Blewitt NJ, Boddie HG, Bradley JH, Braidwood L, Bremner AD, Brown ID, Brown MM, Campbell AM, Campbell J, Carne DR, Carpenter SF, Carr WD, Cartmel RM, Chalmers AJ, Chandra U, Chattopadhyay PK, Chauhdry MS Cheridjian VE, Clark MC, Clark WIC, Cleleand PG, Coladangelo RC, Compson LJ, Corrighan GA, Costello FT, Coladangelo RC, Compson LJ, Corrighan GA, Costello FT,
Counihan RG, Cowlard RJ, Cox MH, Cull RE, Cuthbertson Counihan RG, Cowlard RJ, Cox MH, Cull RE, Cuthbertson
PJR, Daengsvang PADC, Dalton PG, Davidson DLW, Davies EJR, Daengsvang PADC, Dalton PG, Davidson DLW, Davies E, Davies GP, Davies EGL, Davis KJ, Debney FWD, Drake LA, Duggal AN, Dunbar AP, Edgley JN, Evans EC, Faruqi
MT, Fearns SN, Feld MS, Fell PJ, Flynn JF, Ford GC, Gale AN, Ganguli A, Gerg RK, Gibson DA, Glass J, Glover M, Godfrey JJ, Gordon DH, Gostling AC, Goves JR, Gowling GE, Graham RD, Hamill JS, Handa Sk, Hanany WF, Harding MJ, Hargrave DC, Harries AI, Harries IG, Hartill SA, Haugney MGJ, Hawker H, Hennessy TD, Herd EJ, Hewett MF, Hirst AM, Horsfield P, Hudgson P, Hutchinson I, Hutchinson G Hyatt-Williams R, Hyde JC, Jackson NR, Jackson EP, Jafr SKA, Janikiewicz SMJS, Jefferson D, Jennings J, Johnson ML, Jones JP, Jones HHG, Jones DG, Kanungo SM, Khan MA, Kilgallon B, Krasner EB, Lakhani DN, Langridge DA, Lawrence RS, Lloyd RS, Loizou LA, Long RJ, Macauley SJ, MacIntosh NJ, MacLean MH, Mahamood K, Marazzi PJM, Marshall AH, Martin HM, Martin C, McGarrity C, McHattie AG, McInnes GK, McLaren GI, McWilliams JG, Messing HJ, Mitchell DG, Mittal VK, Mooney PN, Moore AC, Morgan
GF, Muggleton RJ, Multani SS, Mutch MW, Nagle PJ, Nahami GR, Nath BK, Nicholas ME, Nightingale MD, NorthCoombes DP, Nutley PG, O'Horan P, Parkinson K, ParrBurman SJ, Patel KS, Patel JA, Patel VA, Patel NH, Pearce RLV, Pilpel JM, Plant NA, Prasad YN, Price E, Price WH, Ralphs GJG, Rees-Jones DI, Reid JJ, Rodger GN, Rogers Sacks GE, Sadler SJ, Salter DHR, Samal K, Scott RJ, Selfridge DI, Servant JB, Seth AK, Sharples PE, Shaw G, Sinclair NM Smith F, Smye RA, Steiner NBM, Steiner RR, Stoy NS Swales VS, Tandon PK, Tarrant PD, Thomas MJ, Thomas SJ, Thornton PW, Till RJW, Tobias JA, Trueman MD, Udal MS Vasan S, Vose MA, Wlaker JA, Ward RJ, Warren KE, Webb EJ, Whiting AJ, Williams AP, Williams PH, Williams JAG, Wood IHY, Wright MHG, Wright J, Wyper DJ, Young BS, Zachariah J.

1 Humphrey PPA, Fenuik W. Mode of action of the antimigraine drug sumatriptan. Trends Pharmacol Sci 1991; $12: 444-6$

2 Hamel E, Fan E, Linville D, Ting V, Villemure J, Chia LS. Expression of mRNA for the serotonin 5-hydroxytryptamine $1 \mathrm{Db}$ Receptor subtype in human and bovine cerebral arteries. Mol Pharmacol 1993;44:242-6.

3 Pilgrim AJ, Blakeborough P. The clinical efficacy of sumatriptan in the acute treatment of migraine. Reviews of Contemporary Pharmacotherapy 1994;5:295-309.

4 Simmons VE, Blakeborough P. The safety profile of sumatriptan in the acute treatment of migraine. Reviews of Contemporary Pharmacotherapy 1994;5:319-28.

5 Cady RK, Wendt JK, Kirchner JR, Sargent JD, Rothrock $\mathrm{JF}$, et al. Treatment of acute migraine with subcutaneous sumatriptan. $\mathscr{f} A M A$ 1991;265:2831-5.

6 The Subcutaneous Sumatriptan International Study Group. Treatment of migraine attacks with sumatriptan. Group. Treatment of migraine
N Engl f Med 1991;325:316-21.

7 The Sumatriptan Auto-injector Study Group. Self-treatment of acute migraine with subcutaneous sumatriptan ment of acute migraine with subcutaneous sumatriptan using a

8 O'Callaghan J, for the Study Group. Long-term efficacy of subcutaneous sumatriptan using a novel self-injector. Cephalalgia 1993;13(suppl 13):161.

9 Headache Classification Committee of the International Headache Society. Classification and diagnostic criteria for headache disorders, cranial neuralgias and facial pain Cephalalgia 198;8(suppl 7):19-28.

10 Machin D, Campbell MJ. Statistical tables for the design of clinical trials. Oxford: Blackwell Scientific, 1987.

11 Cleland PG, Barnes D, Elrington GM, Schapira AHV. Does Pizotifen prophylaxis improve migraine beyond the 
benefit offered by sumatriptan therapy? Cephalalgia 1995; 15(suppl 14):263

12 Fowler PA, Lacey LF, Thomas M, Keene ON, Tanner RJN, Baber NS. The clinical pharmacology, pharmacokinJN, Baber NS. The clinical pharmacology, pharmacokinetics and

13 Blau JN. Sumatriptan and the recurrence of migraine. Lancet 1992;340:1110

14 Mathew NT. Drug-induced headache. Neurol Clin 1990; 8:903-12.

15 Mathew NT, Kurman R, Perez F. Drug-induced refractory headache-clinical features and management. Headache 1990;30:634-8.

16 Tansey MJB, Pilgrim AJ, Martin PM. Long-term experience with sumatriptan in the treatment of migraine. Eur ence with sumatriptan

17 Catarci T, Fiacco F, Argentino C, Sette G, Cerbo R Ergotamine-induced headache can be sustained by sumaErgotamine-induced headache can be sustained by

18 Catarci T, Lenzi GL, Cerbo R, Fieschi C. Sumatriptan and daily headache. $\mathcal{f}$ Neurol Neorosurg Psychiatry 1995;58: 508.

\section{HISTORICAL NOTES}

\section{Octave Landry's ascending paralysis and the Landry-Guillain- Barré-Strohl syndrome}

Jean Baptiste Octave Landry de Théizillat (1826-65) was born in Limoges. He was greatly influenced in starting the study of medicine by his uncle, the neuropsychiatrist $\mathrm{Dr}$ de Thézillat. While still a trainee physician under Sandras and Gubler at the Hôtel Dieu and Hôpital Beaujon in 1852, he showed that muscular activity, both active and passive, depended on afferent relays derived from muscles: "sens de l'activité". This important notion foreshadowed by three years the same conclusion reached by Duchenne and Bellion.

In 1859 he published the first volume of his Traite complet des paralysies. And, in the same year his famous memoir on "ascending paralysis" recorded 10 patients, including five whom he had personally attended; three died, two at the height of the illness, one some months later. He described three types of presentation: ascending paralysis without sensory signs or symptoms; ascending paralysis with concomitant ascending anaesthesia and analgesia; and a progressive generalised disorder characterised by paralysis and sensory loss.

Landry described the illness that he called "ascending paralysis", 1 in a 43 year old paver. After premonitory fever, malaise, and pain in the limbs, on 1 Jure he walked to hospital complaining of "weakness, formications in the tips of his fingers and toes". There was no cramp, spinal pain or sphincter disturbance. Touch was lost in the feet but was little impaired in the upper two thirds of the lower limbs; it was absent in the finger tips.

The paralysis ascended, with formications and sensory loss: "like a band around the affected parts". He had to be supported when standing by his bed. By the third week his limbs were paralysed, he developed diffculty in breathing, chewing, and swallowing, accompanied by fever and coughing. Touch was lost in the feet and impaired in the finger tips, but, "pain and temperature sensation were not altered anywhere". The paver perished in the third week. The location of his illness in the peripheral nerves remained undiscovered, for the necropsy included histological examination only of the cord and soleus muscle. Gubler examined and commented on the case drawing a parallel with diphtheritic paralysis; he mentioned exhaustion of the nervous system and permanent defects of innervation, but having come so close to the truth, curiously, failed to examine the peripheral nerves.

Samuel Wilks furnished details of nine such cases of ascending paralysis, recorded in his book in the chapter on the spinal cord; but its peripheral neural origin was not suspected. Wilks thought "it might be due to a reflex paralysis in which the cord is in no way structurally altered, and therefore may at any time recover..."2

Polyneuropathy is a recent name replacing Ernst von Leyden's (1832-1910) term "multiple neuritis". The first account was probably one of beriberi neuritis described by Bontius in $1642 .{ }^{4}$ Robert Graves in 1843 deserves credit for first implicating disease of the peripheral nerves as a cause of paralysis. ${ }^{5}$ While in Paris in 1828 Graves observed the remarkable epidemic of acute sensorimotor polyneuropathy, aetiologically still obscure. Described by Auguste-Francois Chomel, ${ }^{6}$ it was known as épidémie de Paris. Graves' account in 1843 is to be found in his Clinical Lectures. ${ }^{7}$

In 1876 Westphal referred to "Landry's ascending paralysis". Five years after Landry's account Louis Dumenil (1823-1890) provided the first account of the peripheral nerve pathology in four patients and in six published reports. His first was a 71 year old stone cutter afflicted by a Landry's type of neuropathy:

"a genuine atrophy of the medullary substance of the peripheral nerve tubes and related loss of transverse striations of shrunken muscle fibres in the periphery."8 